\title{
Conflitos de interesses e autonomia na relação entre adolescente grávida e o responsável legal: a antecipação terapêutica na gestação de feto anencefálico
}

Conflicts of interest and autonomy in the relationship between pregnant adolescent and legal guardian: the therapeutic anticipation in anencephalic fetus

Conflictos de intereses y autonomía en la relación entre adolescente embarazada y el responsable legal: la anticipación terapéutica en la gestación de feto anencefálico

Meiriany Lima ${ }^{1}$

Miguel Ângelo Montagner²

\begin{abstract}
Resumo
Objetivo: evidenciar o conflito normativo sobre a capacidade da adolescente grávida de feto anencefálico e o não respeito a sua capacidade autônoma na tomada de decisões. Metodologia: foi utilizada análise documental, revisão bibliográfica e legislativa. A população estudada pertence à faixa etária compreendida entre 12 anos e 17 anos, por ser definida no Código Civil Brasileiro, respectivamente, como fases de incapacidade absoluta e capacidade parcial para atos da vida civil. Resultados: necessidade da construção de propostas de ação que garantam capacidade autônoma às adolescentes sobre o exercício do seu direito à privacidade e à saúde.
\end{abstract}

Palavras-chave: Adolescente. Autonomia profissional. Aborto. Conflito de interesses.

\begin{abstract}
Objective: highlight the normative conflict about the capacity of pregnant adolescent anencephalic fetus and the lack of respect for their autonomous capacity in decision making. Methodology: documentary analysis with bibliographical and legislative revision. The population studied belongs to the age range between 12 years and 17 years, since it is defined in the Brazilian Civil Code respectively as: phases of absolute incapacity and partial capacity for acts of civil life. Results: need to construct proposals for action that guarantee the adolescentes their autonomous capacity on the exercise of their right to privacy and health.
\end{abstract}

Keywords: Adolescent. Personal autonomy. Abortion. Conflict of interest.

\section{Resumen}

Objetivo: evidenciar el conflicto normativo sobre la capacidad de la adolescente embarazada de feto anencefálico y el no respeto a su capacidad autónoma en la toma de decisiones. Metodología: se utilizó análisis documental, con realización revisión bibliográfica y legislativa. La población estudiada pertence a la franja etaria comprendida entre 12 años y 17 años, por ser definida en el Código Civil Brasileño respectivamente

\footnotetext{
${ }^{1}$ Mestranda no Programa de Pós-graduação de Bioética Cátedra UNESCO na Universidade de Brasília (UnB). Advogada e servidora pública da Fundação Universitária de Brasília. Especialista em Direito Sanitário (Fiocruz/Brasília). Brasília, Distrito Federal. Brasil. E-mail: pbslima@hotmail.com

2 Professor Associado da Universidade de Brasília. Sociólogo, Doutor e Mestre em Saúde Coletiva. Coordenador do Observatório de Saúde de Populações em Vulnerabilidade. Brasília, Distrito Federal. Brasil. E-mail: montagner@hotmail.com
} 
como: fases de incapacidad absoluta y capacidad parcial para actos de la vida civil. Resultados: necesidad de la construcción de propuestas de acción que garantan la capacidad autónoma de las adolescentes sobre el ejercicio de su derecho a la privacidad ya la salud.

Palabras-Ilave: Adolescente. Autonomía profesional. Aborto. Conflicto de intereses.

\section{Introdução}

A bioética busca refletir sobre várias temáticas construídas no meio social, dentre elas o eixo saúde-direito, que muitas vezes reverberam em implicações morais e dilemas éticos.

Em casos de gestação de feto anencefálico a proposta de intervenção cunhada como antecipação terapêutica do parto - termo este proposto pela antropóloga Débora Diniz - causa desconforto entre profissionais da saúde e os pares envolvidos na gestação, sendo necessário, em alguns casos, recorrer ao judiciário para garantir o direito das adolescentes à antecipação terapêutica. Trata-se de uma anomalia incompatível com a vida, frequente no Brasil.

A adolescência pode ser considerada como sendo um "período crítico" da existência humana, pois se identifica com a ocorrência de vários contextos de conflito em que as diretrizes e ou preceitos normativos mostram-se ineficazes para solucionar às demandas éticas. Parte desses conflitos resvalam no respeito à decisão autônoma da adolescente grávida em seguir com a gestação ou optar pela interrupção, pois envolvem seus responsáveis legais e toda a equipe de saúde, e muitas vezes o Estado.

Por vezes a capacidade para tomada de decisões autônomas do adolescente é mitigada por normas retrógradas que inviabilizam o exercício pleno de direitos desse indivíduo enquanto ser autônomo. Ao lidar com direitos e vida deve-se sempre ter como cerne o melhor interesse do indivíduo, nesse caso, a adolescente grávida de feto anencefálico. Respeitar a autonomia sobre seu corpo e vida é reconhecer sua liberdade de escolha, respeitando a dignidade, pois o conceito de dignidade não pode ser reduzido ao conceito jurídico nacional de capacidade plena, mitigando ou aniquilando os fundamentos de direitos humanos.

Autonomia pode ser definida como autodeterminação; autogestão; possuir liberdade de escolha de maneira individual e apartado de qualquer tipo de cerceamento ou pressão (1). O respeito às decisões autônomas pode ser categorizado sob três ângulos: o libertarismo, onde a capacidade é considerada como norteador das decisões, 
independentemente da idade biológica; o protecionismo, onde a necessidade de intervenção será permitida quando necessário evitar e ou prevenir riscos ao indivíduo; e o paternalismo, onde o responsável legal promoverá a representação nas decisões até a maioridade legal (2).

A assistência médica a adolescentes grávidas tornou-se um dilema bioético por haver um importante e significativo antagonismo entre o arcabouço normativo pátrio e o reconhecimento prático das adolescentes enquanto sujeito capaz de decisões autônomas sobre seu corpo e vida, fato que acaba se tornando uma questão de saúde pública. Segundo Santos apud Souza, aproximadamente 16 milhões de meninas entre 15 e 19 anos e um milhão abaixo de 15 anos da população mundial parem anualmente, estando a maior concentração dessa população nos países periféricos e em desenvolvimento (3). De acordo com a Sociedade Brasileira para o Progresso da Ciência (SBPC) o Brasil ocupa a quarta posição mundial entre os países com frequência em casos de anencefalia (3). Anencefalia pode ser definida como sendo uma malformação incompatível com a vida fora do útero materno: corresponde ao não fechamento do tubo neural, provocando a exposição da massa encefálica ao líquido amniótico e destruição cerebral e impedindo uma nova formação; o diagnóstico ocorre nas primeiras semanas de gestação (4).

Mesmo diante da incompatibilidade com a vida, as gestantes de feto anencefálico, no período anterior ao posicionamento da Suprema Corte acerca da Ação de Arguição de Descumprimento de Preceito Fundamental $n^{\circ} 54$ (ADPF 54), necessitavam recorrer à autorização judicial para antecipação do parto de feto anencefálico, o que por vezes era denegado judicialmente.

Um caso que ilustra de forma adequada o conflito existente na época foi a peregrinação da agricultora Severina, de Chã Grande, cidade do brejo pernambucano, protagonista do documentário Uma História Severina. Grávida de 14 semanas de feto anencefálico, vivenciou uma verdadeira peregrinação entre idas e vindas aos tribunais e hospitais, até que, em 2004, a liminar que autorizava o aborto de feto anencefálico foi cancelada pelo Supremo Tribunal Federal até nova autorização por liminar, em 2005, autorizando finalmente o procedimento (3) (4).

Em 2004, a Confederação Nacional dos Trabalhadores da Saúde (CNTS) impetrou a Ação de ADPF 54. A motivação para essa ação decorreu da busca ao Poder Judiciário por 
uma gestante, de 18 anos, com feto anencefálico, que desejava interromper a gestação em curso, porém o parto ocorreu antes que a decisão fosse proferida (3) (4).

Consequentemente, a antecipação terapêutica do parto por feto anencefálico foi alvo de intensa discussão judicial no período compreendido entre 2004 e 2012, quando o Superior Tribunal Federal se posicionou de maneira favorável ao direito de a mulher decidir sobre a interrupção ou continuidade gestacional em caso de feto anencefálico, direito esse objeto da ADPF 54 (3) (5). Para além da decisão sobre a interrupção ou não da gestação de feto anencefálico, essa discussão coloca, para os vários segmentos envolvidos, dilemas bioéticos que envolvem o respeito a decisões autônomas de um grupo específico - as adolescentes -, pois em alguns momentos esse grupo terá sua autonomia mitigada pelo conflito de interesses com seus responsáveis legais e necessitará recorrer à tutela do Estado, uma vez que a capacidade da criança e do adolescente no Brasil encontra-se descrita e limitada por um ordenamento jurídico excludente e obsoleto (5).

\section{Discussão}

Pensar autonomia desconsiderando capacidade torna-se uma discussão inócua, pois a evolução humana não ocorre aos saltos, trata-se de processo continuado, marcado por etapas e variações individuais onde ocorrem a conquista de habilidades, essas, por seu turno, permeadas pelas ferramentas fornecidas pelo ambiente sociocultural em que o mesmo se encontra inserido. Portanto, atingir a capacidade plena para decisões autônomas é um processo difuso que se consolida ao longo do percurso.

Atualmente o ordenamento jurídico pátrio pode ser considerado anacrônico quando reduz a capacidade a um lapso temporal e desconsidera a idiossincrasia do discernimento, do entendimento e da clareza que demonstram para a equipe de saúde ser ou não o adolescente capaz de decisões autônomas (6). Um exemplo do respeito às decisões autônomas envolvendo adolescentes e saúde reprodutiva é o caso Gillick, julgado pela House of Lords da Inglaterra e que validou o consentimento da criança menor de 16 anos, desde que sua capacidade de maturidade e compreensão sobre as consequências da terapêutica proposta sejam arrazoadas de maneira coerente, independentemente da oposição do seu responsável legal (7).

O indivíduo, para ser considerado um cidadão capaz, precisa apresentar atitudes autônomas perante a sociedade que estejam abarcadas pelas regras socialmente 
estabelecidas (8). Para Habermas, a resolução de um conflito ético necessita de uma construção dialética entre as partes, como garantia da legitimidade nas decisões terapêuticas (9).

O comitê da Convenção sobre Eliminação de Todas as Formas de Discriminação contra a Mulher (CEDAW) considera a saúde reprodutiva como direito básico das mulheres, garantindo a realização da antecipação terapêutica do parto nos casos de gravidez de feto anencefálico para as mulheres e adolescentes, sendo, para tanto, indispensável o consentimento da paciente ou seu responsável legal conforme previsão normativa (10). De acordo com o Código Civil brasileiro, a adolescente entre 16 e 17 anos deverá ser considerada parcialmente capaz, enquanto a adolescente antes dos 16 anos é considerada incapaz de decisões, tendo, portanto, seu responsável legal que consentir por ela (11).

O Estatuto da Criança e do Adolescente descreve criança como sendo abaixo de 12 anos de idade; adolescente entre 12 e 17 anos, entretanto faz a ressalva de que deve prevalecer o respeito à vontade dos mesmos (12).

De acordo com o artigo 74, do Código de Ética Médica:

"É vedado ao médico revelar segredo profissional referente à paciente menor de idade, inclusive a seus pais ou responsáveis legais, desde que o menor tenha capacidade de avaliar seu problema e de conduzir-se por seus próprios meios para solucioná-los, salvo quando a não revelação possa acarretar danos ao paciente" (CFM, 2010) (13). [grifos nossos]

Conforme a norma técnica de 2014 acerca da atenção à saúde das mulheres grávidas de feto anencefálico, emitida pelo Ministério da Saúde, quando se tratar de adolescentes, no conflito de interesses, a vontade da adolescente deverá ser respeitada, mesmo que sua decisão contrarie a de seus responsáveis legais. Caso estes se recusem a assinar o consentimento, o serviço de saúde deverá - se entender que a adolescente é capaz para tal decisão - delegar ao Estado, por meio da autoridade judicial competente, a decisão sobre acatar ou não a decisão da adolescente grávida. Reza a norma:

a) Respeitar o direito à autodeterminação de todos os pacientes, homens ou mulheres, como dispõe a "Declaração da Associação Médica Mundial sobre os Direitos do Paciente", adotada na $34^{\circ}$ Assembleia Médica Mundial, em 1981, 14 em Lisboa (Portugal), e emendada na $47^{\circ}$ Assembleia Geral, no ano de 1995, na cidade de Bali (Indonésia). 
b) Respeitar o direito à autonomia dos pacientes e das pacientes, nos termos do artigo $7^{\circ}$ da Lei Orgânica da Saúde (Lei $n^{\circ} 8.080$, de 19 de setembro de 1990), que dispõe que "as ações e serviços públicos de saúde e os serviços contratados ou conveniados que integram o SUS, são desenvolvidos de acordo com as diretrizes previstas no artigo 198 da Constituição Federal, obedecendo ainda aos seguintes princípios: (...) III Preservação da autonomia das pessoas na defesa de sua integridade física e moral".

c) Atuar sempre em benefício do paciente, seja homem ou mulher, respeitando a sua dignidade, a sua autodeterminação e a sua autonomia (CEM Princípios Fundamentais, Capítulo I, itens V, VI e XVII e Capítulo IV, art. 28); e

d) Respeitar o direito de decidir dos pacientes e das pacientes sobre a sua pessoa ou seu bem-estar, sendo defeso exercer a sua autoridade para limitar esse direito ou criar qualquer dificuldade para o seu exercício (CEM art. 24, Capítulo IV) (10). [grifos nossos]

Observa-se que existe um aparente conflito legal no tocante à capacidade para a tomada de decisões implicando adolescentes e ou crianças, pois, apesar de ser o Brasil signatário dos Tratados de Direitos Humanos, em alguns momentos será praticada uma violação a esses direitos considerados fundamentais.

A bioética, como uma de suas características, fomenta e subsidia discussões envolvendo a saúde dos indivíduos para buscar a construção das possíveis soluções frente aos dilemas éticos sociais (14). Portanto, o não respeito à decisão autônoma da adolescente grávida de feto anencefálico pode ser enquadrado como tratamento desumano ou degradante, por lhe impor uma demora ocasionada pela espera de uma decisão judicial, ou por prolongar uma condição de intenso sofrimento psíquico e emocional ao ter sua decisão suprimida e ser obrigada a conviver com o risco de possível dano físico (7).

Não é possível considerar uma construção ética adstrita a critérios legais ultrapassados; faz-se necessário avaliar o grau de sofrimento psíquico, emocional e físico a qual uma gestação de feto anencefálico pode desencadear. Albuquerque propõe uma averiguação do grau de maturidade da criança e do adolescente para então decidir sobre a ampliação ou restrição no processo de tomada de decisão sobre a terapêutica proposta, assim como a legislação pátria deve adotar instrumentos que viabilizem a efetividade da participação da criança e do adolescente (7). 


\section{Breves considerações}

Durante o levantamento do material bibliográfico e legislativo a ser utilizado para construção deste debate, evidenciou-se que o tema proposto surge de maneira tímida no cenário nacional. Apesar das parcas legislações que versam sobre o direito dessa adolescente gestante de feto anencefálico, pode-se observar primariamente o conflito legislativo para a aplicação da norma: a ausência de garantia ao direito de decisões sobre o próprio corpo; o transtorno, transitórios ou permanentes, que tais conflitos podem ocasionar à adolescente; e a espera por uma decisão das autoridades competentes resultando em uma forma de tratamento desumano ou degradante.

Também são ações em evidência como resultado desta pesquisa a ausência de ações céleres no atendimento à adolescente grávida de feto anencefálico; a necessidade em promover uma abordagem funcional do conceito de capacidade adotado em nosso ordenamento pátrio; e a construção de uma nova concepção de capacidade no ordenamento jurídico pátrio.

Não falar sobre a saúde reprodutiva das adolescentes chega a ser pueril, o fato está posto e precisa ser debatido para a construção de ações eficientes que contemplem esse grupo. Respeitar as decisões autônomas da adolescente grávida de feto anencefálico quando em conflito com seu responsável legal significa evidenciar sua capacidade e competência para decisões sobre sua privacidade, e conceder-lhe um lugar de fala na sociedade que fecha os olhos e restringe os debates ao campo da conveniência jurídica.

\section{Referências}

1. Beauchamp TL, Childress JF. The Principles of biomedical ethics. 4ed. New York: Oxford, 1994.

2. Figueira ACS. Consentimento e proteção de adultos e crianças: dilemas comuns e peculiares em países em desenvolvimento. Revista Bioética 2010; 18(3): 691 - 703. PDF.

3. Barbosa MAC, Moreira VF, Suanne ENC. O direito a interrupção da gravidez de fetos anencéfalos: vozes e logicas discursivas presentes na ADPF 54. Política e Sociedade. Florianópolis; Mai./Ago. 2014; 13(27). PDF.

4. Diniz D, Vélez ACG. O aborto e a razão pública: O desafio da anencefalia no Brasil. Disponível em: http://www.bibliotekevirtual.org/index.php/2013-02-07-03-02-35/2013-02-0703-03-11/2014-07-19-06-15-59/504-mandragora/v13n13/6500-aborto-e-razao-publica-odesafio-da-anencefalia-no-brasil.html [Acesso em 3. Jun.2018]. 
5. Diniz D. Selective abortion in Brazil: the anencephaly case. Developing World Bioethics;2007d;7(2)21-28, 2. Disponível em: http://dx.doi.org/10.1111/j.14718847.2007.00202.x [Acesso em 3. Jun.2018].

6. Leone C. A criança o adolescente e a autonomia. Revista Bioética,2010;6(1). Disponível em:http://revistabioetica.cfm.org.br/index.php/revista_bioetica/article/view/324 [Acesso em 3. Jun.2018].

7. Albuquerque A. Direitos humanos dos pacientes. Curitiba: Juruá, 2016.

8. Agambem D. Por uma Teoria do Poder Destituinte, de Giorgio Agamben. Palestra pública em Atenas, 16.11.2013. (Convite e organização pelo instituto Nicos Poulantzas e pela juventude do SYRIZA).

9. Pinho HDB, Durço KA. A mediação e a solução dos conflitos no Estado democrático de direito. Revista eletrônica de direito processual civil. $2^{\mathrm{a}}$ edição. Disponível em: http://www.e-publicacoes.uerj.br/index.php/redp/article/viewFile/23719/16748 [Acesso em 28.maio.2018].

10. Brasil. Ministério da Saúde. Secretaria de Atenção à Saúde. Departamento de Ações Programáticas Estratégicas. Atenção às mulheres com gestação de anencefálicos: norma técnica, Secretaria de Atenção à Saúde, Departamento de Ações Programáticas Estratégicas. Série Direitos Sexuais e Direitos Reprodutivos(11). Brasília: Ministério da Saúde, 2014. Disponível em: https://brasil.mylex.net/legislacao/codigo-civil-ccart4_1721.html [Acesso em 28. Maio. 2018].

11. Brasil. Código Civil de 2002. Lei $n^{\circ} 10.406$ de 10 de Janeiro de 2002. Disponível em: https://brasil.mylex.net/legislacao/codigo-civil-cc-art4_1721.html [Acesso em 10. jun. 2018].

12. Brasil. Estatuto da Criança e do Adolescente - Lei no 8.069, de 13 de julho de 1990. Disponível em: https://presrepublica.jusbrasil.com.br/legislacao/91764/estatuto-da-criancae-do-adolescente-lei-8069-90 [Acesso em 10.jun.2018].

13. Código de Ética Médica, CFM 2017. Disponível em: http://www.rcem.cfm.org.br/ index.php/cem-atual\#cap9 [Acesso em 10.jun.2018].

14. Junior EVS, Silva VSB, Lozado YA, Bomfim ES, Alves JP, Boery EM, Boery RNSO. Dilemas bioéticos na assistência médica às gestantes adolescentes. Revista bioética.2018; 26 (1): $87-94$

15. Brasil. Arguição de Descumprimento de Preceito Fundamental 54 Distrito Federal. Disponível em: http://www.stf.jus.br/arquivo/cms/noticianoticiastf/anexo/adpf54.pdf [Acesso em 28. Maio. 2018].

16. Chaves JHB, Pessini L, Bezerra AFS, Rego G. Abortamento provocado na adolescência sob uma perspectiva bioética. Rev. Bras. Saúde Mater. Infantil. Dez 2010(10) (supl.2),311-s319. ISSN 1519-3829. Disponível em: http://www.scielo.br/scielo.php? pid=S1519-38292010000600008\&script=sci_abstract [Acesso em 1. jun. 2018]. 
17. Chaves JHB, Pessini L, Bezerra AFS, Rego G. A Interrupção da Gravidez na Adolescência: aspectos epidemiológicos numa maternidade pública no nordeste do Brasil. Saúde Sociedade. São Paulo:2012; 21(1)246-256. Disponível em: http://www.scielo.br/pdf/ sausoc/v21n1/23.pdf [Acesso em 1.jun.2018].

18. Cavalcante A, Xavier D. Aborto uma visão humanística. Estudos Feministas, Florianópolis, maio- agosto/2008;16(2): 691-713. Disponível em: http://www.scielo.br/ scielo.php?script=sci_arttext\&pid=S0104-026X2008000200031 [Acesso em 1.jun.2018].

19. Donnelly M. Healthcare decision-making and the law. Cambridge: Cambridge, 2010.

20. Ely GE, Flaherty C, Cuddeback GS. The Relationship Between Depression and Other Psychosocial Problems in a Sample of Adolescent Pregnancy Termination Patients. Child Adolesc Soc Work J (2010) 27:269-282 PDF

21. Lemos A, Russo JA. Profissionais de saúde e o aborto. Comunicação saúde e educação. 2014; 18 (49) 301-312. PDF

22. Harris J. Relational autonomy and family law. Nova lorque: Springer, 2014. 